\title{
A PI-based Control Scheme for Primary Cascaded H-Bridge Rectifier in Transformerless Traction Converters
}

\author{
Xing-Hua Tao*, Yong-Dong $\mathrm{Li} * *$, and Min Sun**
}

\begin{abstract}
Cascaded H-Bridge rectifier (CHBR) is a more attractive solution in traction application for its transformerless structure. Because of the currents of different cells are exactly the same one, it is a challenge job to regulate the voltages of cells with only one current controller. In this paper, a PI-based control scheme is presented to deal with the voltages balance issue in CHBR. To satisfy the demand of rectifier such as unity power factor and regulated output DC voltages, the proposed control scheme consists of two parts. One is for shaping the grid current waveform and regulating the sum of DC-link voltages of all the cells; the other one is for balancing DC-link voltages. The latter is more concerned in this paper and is discussed in detail especially. Simulations and experiments are carried on. The results verified the feasibility and effectiveness of the proposed scheme.
\end{abstract}

\section{Keywords: Cascaded H-bridge rectifier, voltage balance, transformerless}

\section{Introduction}

Multilevel converter topology is an effective way for us to solve to problem of overcoming the voltage limits imposed by the power semiconductors. By connecting the switching devices in series, it is possible to share the overall supply voltage. The state of the art and the most recent advances in the area of high-power high-voltage multilevel converters are analyzed in [1]. Among all the possible topologies, the cascaded H-bridge (CHB) topology is of special interest due to its modularity, simple lay out and easy control.

In China railways are supplied with a single-phase supply rating up to $25 \mathrm{kV}$. Traditional converters can not stand for such voltage levels and step-down converters are needed to change the supply voltage level to an accepted one. However this kind of low-frequency step-down transformer is expensive, bulky and heavy. What's more, the traditional diode based rectifier injects significant harmonic currents into the power grid. As the power quality is becoming a more and more important concerning issue, PWM rectifiers are chosen as the front converters. The bidirectional power flow ability is also a bonus of the PWM rectifiers.

The structure depicted in Fig. 1 is a very promising structure in traction applications. The voltage-source PW

\footnotetext{
* Dept. of Electrical Engineering, Naval Engineering University, China. (taoxh06@mails.thu.edu.cn)

** Dept. of Electrical Engineering, Tsinghua University, China.(liyd@mail.thu.edu.cn; summit@mit.edu)

Received 06 February 2012 ; Accepted 11 July 2012
}

$\mathrm{M}$ rectifier is connected directly to the power source $\mathrm{b}$ ecause the series connected H-bridge cells share the hi gh voltage. Therefore compared to the conventional hig $\mathrm{h}$ voltage drive system, the bulky and expensive transfor mer could be eliminated through the series connection of the switching devices in such topology.

The control of the front-end cascaded H-bridge rectifier is the main challenge of the structure. Two main requirements need to be achieved:

- $\quad$ to guarantee the ac side unity power factor;

- to maintain the DC-link voltage balance of the output H-bridge cell.

Different power could be transferred from the ac side to the dc sides when the DC-link output can be operated independently. So the DC-link voltage balancing task is difficult. Lots of DC-link voltage balancing methods have been proposed for the CHB based single-phase static compensator (STATCOM) [2]. Unfortunately STATCOM only delivers reactive power from the power supply, so these methods are not applicable in this situation. In [3], the balancing is achieved through a redundancy based modulation strategy; in [4], the balancing is achieved actually through a hysterias controller; in [5], the balancing is achieved through a passivity-based control, which is too complicated.

Unlike the references above, this paper proposes a PIbased solution. A two-cell cascaded H-bridge rectifier is considered here. Simulation results as well as experimental evidences of this method are presented too. 


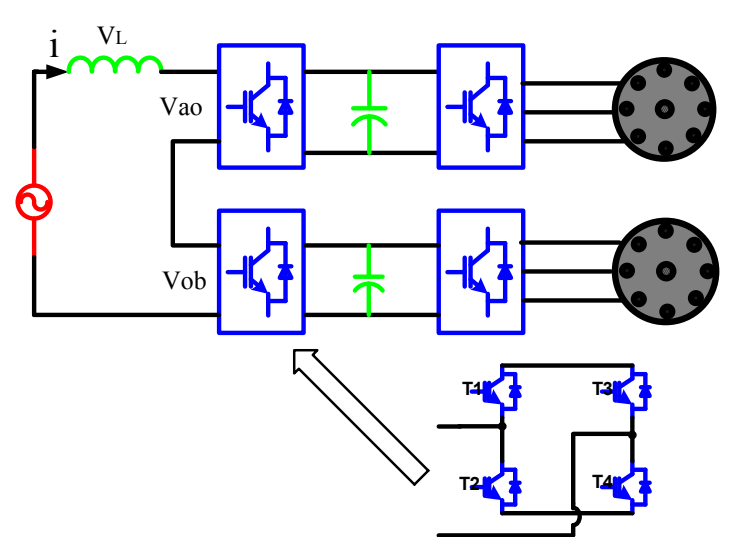

Fig. 1. The structure of transformerless locomotive drive system

\section{Proposal Control Scheme}

\subsection{Mathematic Model of the CHB Rectifier}

The ac side voltages of the H-bridge cell $v_{a o}, v_{o b}$ are determined by:

$$
\begin{aligned}
& v_{a o}=d_{1} V_{d c 1} \\
& v_{o b}=d_{2} V_{d c 2}
\end{aligned}
$$

where $d_{1}, d_{2}$ are the modulation index of each cell.

Actually they are continuous switching functions. The dynamic response of the system is described by the equations of inductance and capacitors:

$$
\begin{gathered}
v_{s}=v_{a o}+v_{o b}+L \frac{d i_{s}}{d t} \\
d_{1} i_{s}=C \frac{d V_{d c 1}}{d t}+\frac{V_{d c 1}}{R_{1}} \\
d_{2} i_{s}=C \frac{d V_{d c 2}}{d t}+\frac{V_{d c 2}}{R_{2}}
\end{gathered}
$$

If the H-bridge cells are replaced by voltage sources, the steady state phasorial diagram of the rectifier can be depicted in Fig.2. It should be noted that there are various combinations of the ac-side voltage phasors $v_{a o}, v_{o b}$, which may have different directions with $v_{a b}$.

The power consumption of each cell is:

$$
\begin{gathered}
p_{1}=v_{a o} i_{s} \\
p_{2}=v_{o b} i_{s}
\end{gathered}
$$

If the ordinary phase shifted PWM method is used in the modulation without special voltage balance algorithm, we have $d_{1}=d_{2}=d$. Equation (6) (7) can be rewritten as:

$$
\begin{gathered}
p_{1}=d V_{d c 1} i_{s}=\frac{V_{d c 1}^{2}}{R_{1}} \\
p_{2}=d V_{d c 2} i_{s}=\frac{V_{d c 2}^{2}}{R_{2}}
\end{gathered}
$$

Note that both cells share the same current. Then we have:

$$
V_{d c 1}: V_{d c 2}=R_{1}: R_{2}
$$

Equation (10) means that the DC-link voltages cannot balance themselves under unbalanced load conditions without special voltage balance algorithms.

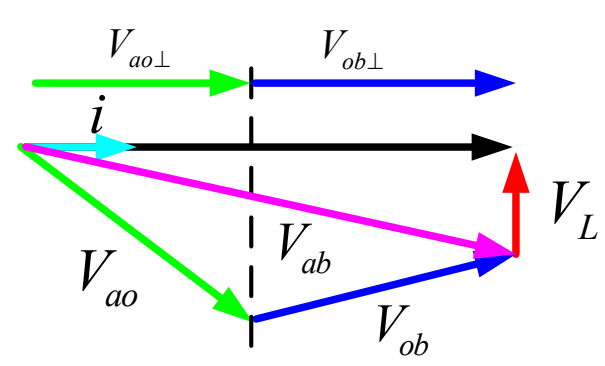

Fig.2. Steady state phasorial diagram of the $\mathrm{CHB}$ rectifier

\subsection{Overall Control Schemes}

The overall control strategy of the cascaded H-bridge rectifier is shown in Fig.3. The sum of the DC-link voltages is controlled through the voltage controller $G_{v}(s)$ (usually an conventional PI controller), the output of which is the command of the current. The phase and magnitude of the voltage source are evaluated by the single-phase PLL. From them is calculated the required instantaneous current command $i_{s}{ }^{*}$, which is compared to the actual current $i_{s}$. The error is sent to the Proportional and Resonant (PR) controller $G_{i}(s)$ [6].The PR current controller can eliminate the error between the current setting signals and the actual current. The form of PR controller is as follows:

$$
G_{i}(s)=K_{p}+\frac{2 K_{i} s}{s^{2}+\omega_{e}^{2}}
$$

Where $\omega_{e}$ is the resonant frequency of the PR controller.

The controller has a conjugate pole of $\pm j \omega_{e}$. The output of the PR controller is the modulation index $d$. 
The voltage balance part can generate the individual modulation index of each cell $d_{1}, d_{2}$. The PWM with shifted carriers is used for the modulation of the CHB rectifiers. The major benefit of this method is the significant decease of the current ripple due to the multilevel nature of the PWM voltage at ac terminals. In this paper, the PWM voltage at the ac side is five-level.

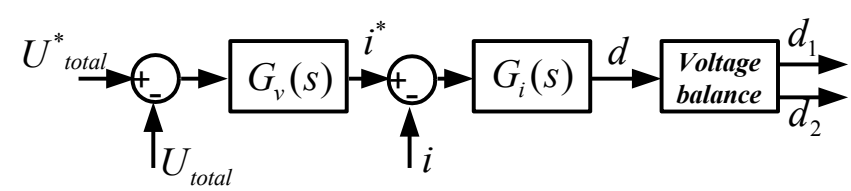

Fig.3. Overall control block of the CHB rectifier

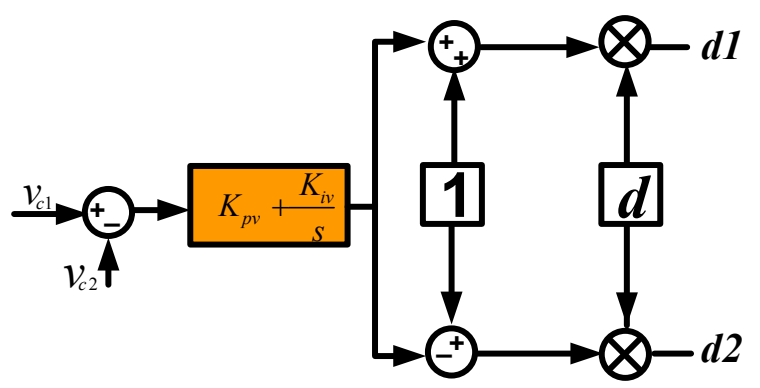

Fig.4. Voltage balance scheme

\subsection{Voltage Balance Scheme}

From the point of energy distribution, the voltage balance control is to control the power flow of the H-bridge cells. In Fig, the active power flowing into the cells are proportional to the projection of the ac-side voltage phasors $v_{a o \perp}, v_{o b \perp}$. Therefore we only need to control $v_{a o \perp}, v_{o b \perp}$ to achieve the voltage balance. The orthogonal components of the voltage phasors provide us a freedom to construct $v_{a o}, v_{o b}$.

In the proposed scheme, we force $v_{a o}, v_{o b}$ to have the same direction with $v_{a b}$. One benefit is that only the magnitudes of $v_{a o}, v_{o b}$ need to be concerned when building the voltage phasors.

If the loads feeding on the DC-link are the same, then the magnitudes of $v_{a o}, v_{o b}$ are the same too. If the loads are not the same, the difference between the two DC-link voltages could be used as the error signal to regulate the magnitudes of $v_{a o}, v_{o b}$. The voltage balance scheme is depicted in Fig.4.

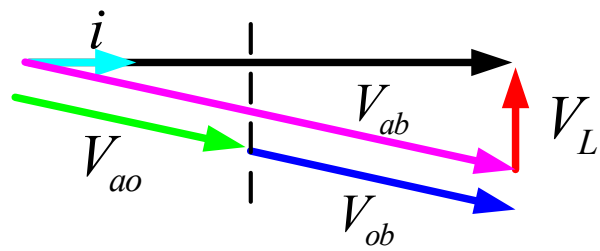

Fig.5. Phasorial diagram of the $\mathrm{CHB}$ rectifier when usi ng the proposed voltage balance scheme

To design the PI controller, suitable transfer functions are obtained through the linearization and simplification of equation (4) and (5).Considering only the dc components of the term $d_{1} i_{s}, d_{2} i_{s}$ [7], equation becomes to:

$$
\begin{gathered}
\frac{d_{1 \max } i_{s \max }}{2}=C \frac{d V_{d c 1}}{d t}+\frac{V_{d c 1}}{R_{1}} \\
\frac{d_{2 \mathrm{ma}} i_{\mathrm{m}}}{2} \stackrel{\mathrm{a} \times}{=} C \frac{d V_{d c}}{d t}+\frac{2 V_{d}}{R}
\end{gathered}
$$

In order to get the transfer function between $d_{\max }$ and $V_{d c}$, the load current could be seen as disturbances and the ac side current is constant:

$$
\frac{V_{d c}(s)}{d_{\max }(s)}=\frac{i_{s \max }}{2 C s}
$$

Then the control block of the voltage balance loop is shown in Fig.6. The PI controller design could be carried out in $s$ domain using root locus method.

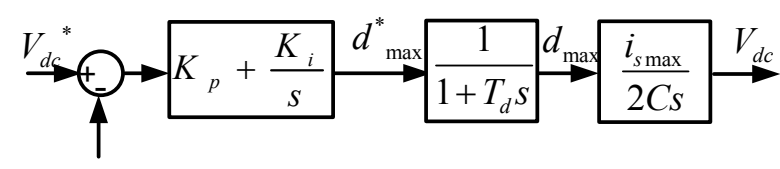

Fig.6. Voltage balance loop block

\section{Simulation and Experimental Results}

The simulation is carried out in Matlab Simulink. The parameter of the cascaded H-bridge rectifier is in Table 1.

Table 1. Parameters of the cascaded H-bridge rectifier

\begin{tabular}{|c|c|}
\hline Switching frequency & $5 \mathrm{kHz}$ \\
\hline Filter inductance (L) & $7.5 \mathrm{mH}$ \\
\hline Filter inductance resistor & $0.2 \Omega$ \\
\hline DC-link capacitor & $2350 \mathrm{uF}$ \\
\hline DC-link load & $150 \Omega$ \\
\hline Voltage source (rms) & $220 \mathrm{~V}$ \\
\hline DC-link voltage references & $225 \mathrm{~V}$ \\
\hline
\end{tabular}

The steady state waveform is shown in Fig.7 and Fig.8. From Fig. 7 we can see that the current is tracking the supply voltage very well and the DC-link voltages are well 
regulated to the goal voltage. Note that there exist $100 \mathrm{~Hz}$ ripples in the DC-link voltage, so the DC-link voltage sample should firstly be processed by a low-pass or notch filter. Otherwise the current command would compose $150 \mathrm{~Hz}$ components. Fig. 8 is the five-level voltage at the ac output of the converter.

Fig.9 and Fig. 10 are the transient waveform during the load step. At $\mathrm{t}=0.05 \mathrm{~s}$ the load of the second cell jumps to 75 $\Omega$. Fig.9 is the ac current and DC-link voltage waveforms. The transient is about $0.9 \mathrm{~s}$. The PI controller is a little slow because of the time delay of the modulator. The modulation signals are shown in Fig.10, from which we can see that when the loads are equivalent the modulation signals of each cell are the same while they would have different magnitudes but same phase when the loads are different.

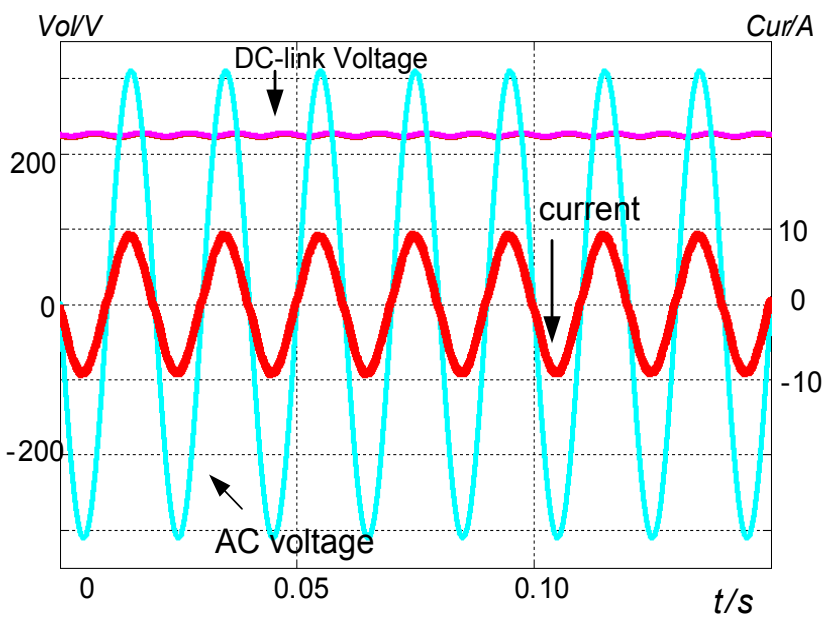

Fig.7. Steady waveform of current, ac voltage and DClink voltages

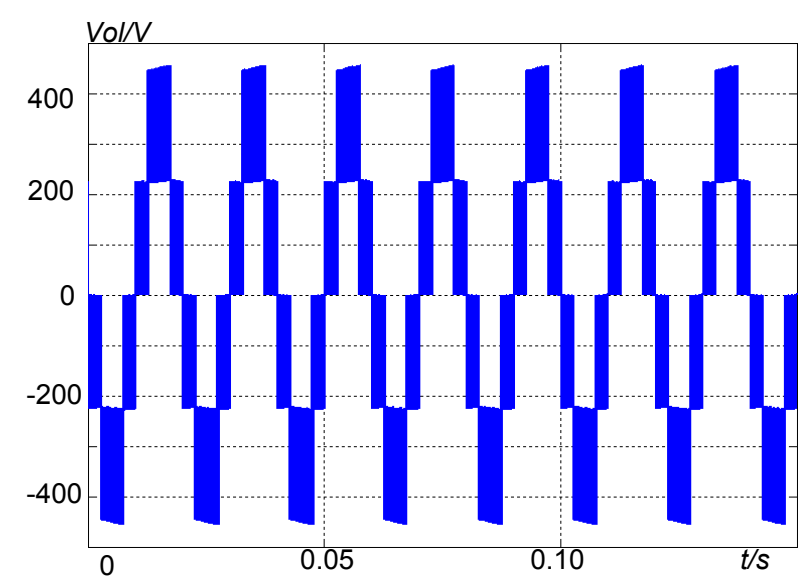

Fig.8. The five-level PWM voltage

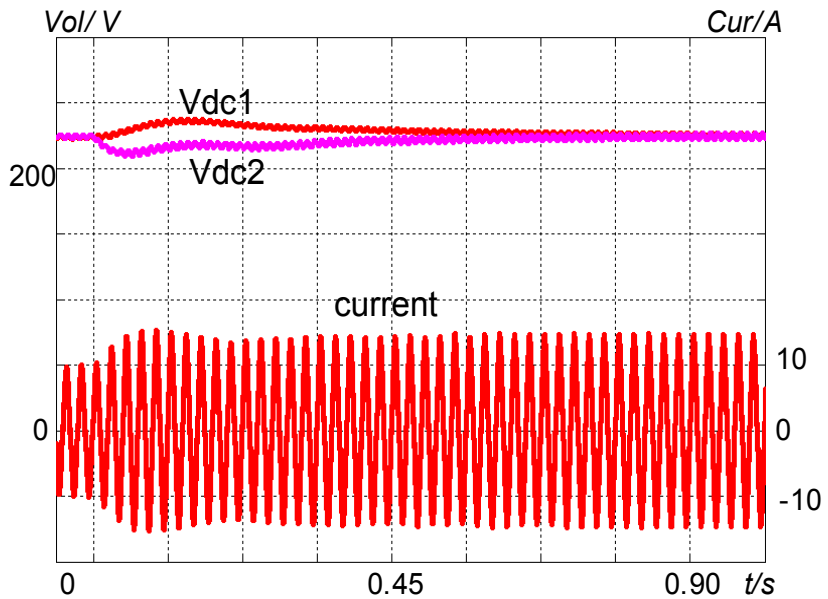

Fig.9. Load step waveform of the DC-link voltage and current

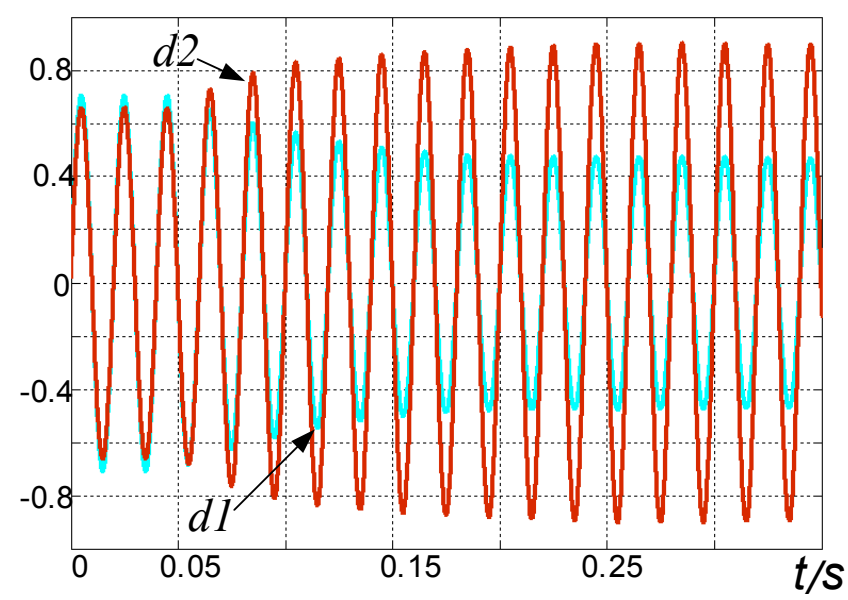

Fig.10. Modulation signals of each H-bridge cell.

A two-cell CHBR prototype is built in laboratory. The parameters are shown as Table 2. The experiments include no-load and full-load operating. Figure.11 illustrates the load step process from no-load to full-load. The CHBR is in steady state before load steps. The DC-link voltages are both equal to the reference voltage $(60 \mathrm{~V})$. Voltage vibrations are almost zero with no load. The steady state is broken when the load is increased suddenly. The two cell's voltages also do not keep balance any more. However, the DC-link voltages are regulated to the reference value in some period by controller. During this transition, the grid current keeps well in phase with the grid voltage. Unity power factor is achieved. Fig.12 is shown the AC side voltage. Five-level waveform is got by phase shift technology. Notice that the vibrations of the DC-link voltages becomes larger when the load is increased, therefore it results little change of $\mathrm{AC}$ side voltage 
compared to the one with no load. Fig.13 demonstrates the transient of DC-link voltages balancing with the load is varied. It again verifies the efficiency of the proposed method.

Table 2. Electrical parameters of the system

\begin{tabular}{|c|c|}
\hline Switching frequency & $5 \mathrm{kHz}$ \\
\hline Filter inductance (L) & $7.5 \mathrm{mH}$ \\
\hline Filter inductance resistor & $0.2 \Omega$ \\
\hline DC-link capacitor & $2350 \mathrm{uF}$ \\
\hline Voltage source (peak value) & $100 \mathrm{~V}$ \\
\hline DC-link voltage references & $60 \mathrm{~V}$ \\
\hline
\end{tabular}

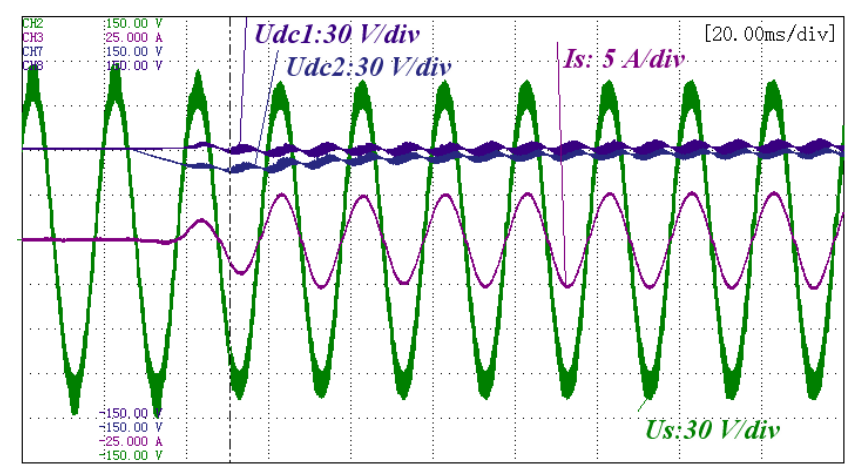

Fig.11. Measured waveform: grid voltage $U_{s}$ and curre nt $I_{s}$; DC-link voltages $U_{d c 1}$ and $U_{d c 2}$.

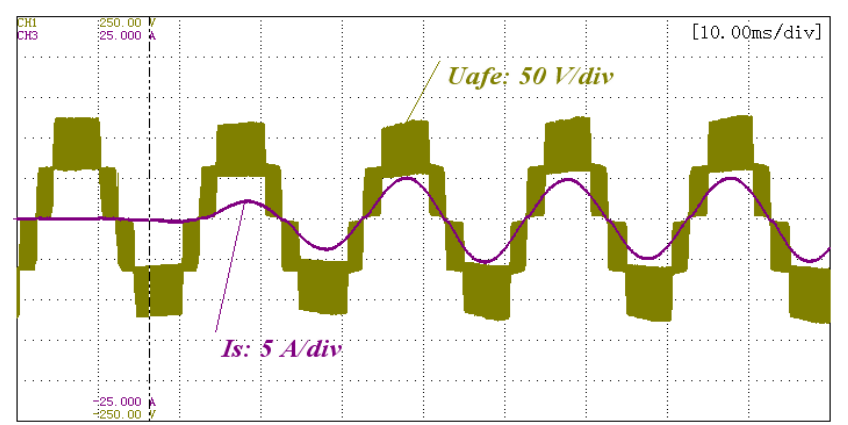

Fig.12. Measured AC side voltage $U_{\text {afe }}$ and grid current $I_{s}$.

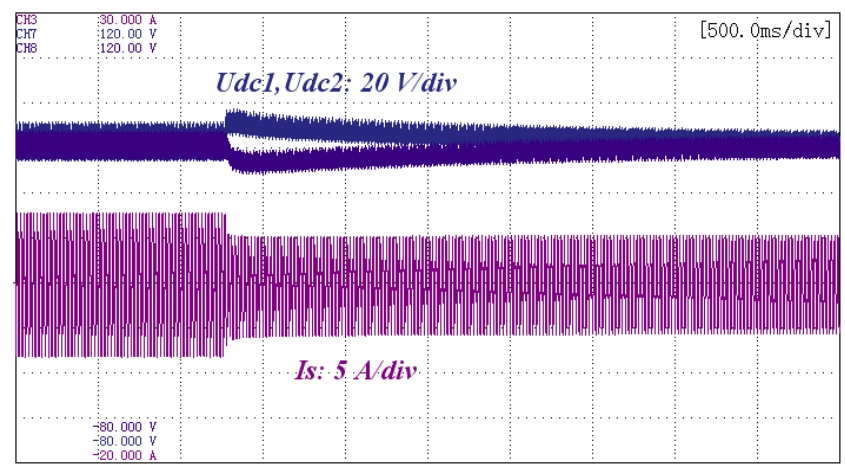

Fig.13. Measured DC-link voltages $U_{d c 1}, U_{d c 2}$ and grid current $I_{s}$

\section{Conclusion}

Cascaded H-bridge rectifier can be used as the active front-end of high voltage and high power multilevel converters. Such structure can eliminate transformers in traditional converter. Therefore it brings significant advantages in volume, weight and cost. To solve voltage balance problem of CHBR, the control strategy of the twocell $\mathrm{CHB}$ converter is presented in this paper. The classic control scheme of single phase PWM rectifier is adopted to regulate the sum of cells' voltages and the grid current. The double-loop controller can guarantee unity power factor and DC voltage regulated to the reference value. Voltages balance achieves with the proposed method, which a PI controller is employed to deal with the voltage error between the measure value and the reference value and generate the regulated modulation index to eliminate the error. The good performance in both simulations and experiments proves the effectiveness of the proposed control scheme to manage power distributions on the $\mathrm{CHB}$ rectifier.

\section{References}

[1] Rodriguez, J.; Franquelo, L.G.; Kouro, S.; Leon, J.I.; Portillo, R.C.; Prats, M.A.M.; et al, "Multilevel Converters: An Enabling Technology for High-Power Applications," Proceedings of the IEEE, Vol. 97, Issue 11, pp. 1786-1817, November 2009

[2] J. A. Barrena, L. Marroyo, M. A. R. Vidal, J. R. Torrrealday, "Individual Voltage Balancing Strategy for PWM Cascaded H-bridge Conveter-Based STATCOM," IEEE Transactions on Industrial Electronics, Vol. 55, No. 1, pp. 21-29, January 2008.

[3] Cecati C, Dell'Aquila A, Liserre M, et al, "Design of Hbridge Multilevel Active Rectifier for Traction Systems," IEEE Transactions on Industry Applications, Vol. 39, No. 5, pp. 1541-1550, May 2003.

[4] Iman-Eini H, Schanen J, Farhangi S, et al. "A Modular Strategy for Control and Voltage Balancing of Cascaded HbridgeRectifiers," IEEE Transactions on Power Electronics, Vol. 23, No. 5, pp. 2428-2442, May 2008.

[5] Cecati C, Dell'Aquila A, Liserre M, et al. "A Passivity-based Multilevel Active Rectifier With Adaptive Ccompensation For Traction Applications," IEEE Transactions on Industry Applications, Vol. 39, No. 5, pp. 1404-1413, May 2003.

[6] Zmood D N, Holmes D G, Bode G H. "Frequency-domain analysis of three-phase linear current regulators," IEEE Transactions on Industry Applications, Vol. 37, No. 2, pp. 601-610, February 2001.

[7] Villanueva E, Correa P, Rodriguez J, et al. "Control of a Single-Phase Cascaded H-Bridge Multilevel Inverter for Grid-Connected Photovoltaic System," IEEE Transactions on 
Industrial Electronics, Vol. 56, No. 11, pp. 4399-4406, November 2008.

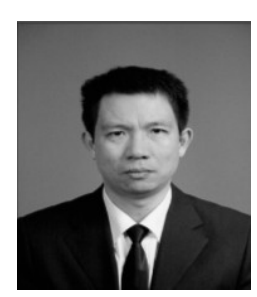

Xing-Hua Tao received Ph.D degree

in electrical engineering from Tsinghua university, Beijing, China. His research interests are multilevel converters and electric machines.

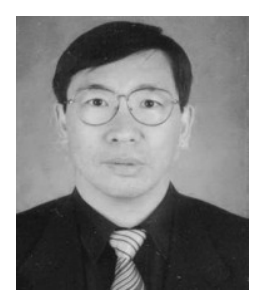

Li Yongdong (M'08) received Ph.D. degrees from the Department of Electrical Engineering, Institute National Polytechnique de Toulouse, France. His research interests include power electronics, power converter topologies, machine control and wind power generation.

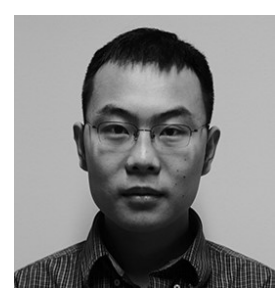

Min Sun received M.S degree in electrical engineering from Tsinghua university, Beijing, China. His research interests are power electronics device and electric machines. 